\title{
Structure and interactions in $\alpha$-crystallin probed through thiol group reactivity
}

\author{
Sudipa Saha ${ }^{1}$, Kali Pada Das ${ }^{2}$ \\ ${ }^{1}$ Department of Biotechnology, St. Xavier's College, Mother Teresa Sarani, Kolkata, India \\ ${ }^{2}$ Department of Chemistry, Bose Institute, Kolkata, India \\ Email: sahasudipa74@yahoo.co.in, kalipada@jcboseinst.ac.in, daskp25@gmail.com
}

Received 27 July 2013; revised 12 September 2013; accepted 28 September 2013

Copyright (C) 2013 Sudipa Saha, Kali Pada Das. This is an open access article distributed under the Creative Commons Attribution License, which permits unrestricted use, distribution, and reproduction in any medium, provided the original work is properly cited.

\begin{abstract}
$\alpha$-Crystallin is the major structural protein of eye lens of vertebrates. In human lens, the ratio of $\alpha \mathrm{A}$ crystallin to $\alpha \mathrm{B}$-crystallin was found to be 3:1. $\alpha \mathrm{A}$ Crystallin contains two cysteine residues at positions 131 and 142, which are at the junction between the $\alpha$-crystallin domain and the C-terminal tail. We used the accessibility of the thiol groups by Ellman's reagent (DTNB) as a tool to gain information about the various structural perturbations of hinge region of $\alpha$-crystallin and during the binding with substrates. In the native condition, the cys-142 though reacted quite fast was not fully exposed. Several reagents were used to see the accessibility of cys-131. Rate constant for cys-131 was increased gradually with increase in the concentration of reagents. The bindings of substrates are affected by the accessibility of thiol indicating that the substrates bind to the hinge region of $\alpha$-crystallin. By blocking of cys-142, it was observed that the accessibility of one thiol depends on the other thiol, and they are not independent. The hinge region of $\alpha$-crystallin is very important as substrate binding site and from this study we have got various structural information about that region.
\end{abstract}

Keywords: Thiol Reactivity; $\alpha$-Crystallin; DTNB Kinetics; Molecular Chaperone; Folding Unfolding of $\alpha$-Crystallin

\section{INTRODUCTION}

Various physico-chemical methods have been explored to gain structural information of $\alpha$-crystallin during its interaction with various substrates or during structural alterations caused by externally applied stress or during its folding/unfolding phenomena [1-4]. Although hydrophobicity measurements are helpful in understanding of interactions between chaperone and substrates, it does not provide pointed information as to the location of the contact regions. Chemical cross-linking of fluorescence label and subsequent sequencing of proteolytic fragments produced information about contact regions in chaperone-substrate interaction [5-7].

In order to understand the chaperone substrate interacttion in detail, the contact regions of $\alpha$-crystallin need to be established. The sequence of $\alpha$-crystallin is broadly divided into $\mathrm{N}$-terminal region consisting of about 60 residues, the $\alpha$-crystallin domain consisting of about 80 90 residues and a C-terminal tail consisting of $25-30$ residues $[4,5,8,9]$. Numerous studies done on $\alpha$-crystallinsubstrate interaction have implicated parts of the $\mathrm{N}$-terminal region as substrate binding site [7,10-12] This region has also been reported to control the oligomeric size of the chaperone [13-16]. The conserved central $\alpha$-crystallin domain is involved in extensive subunit contacts $[5,14]$. However, the spatial expositions of the various segments of this region and its implications for the molecular chaperone function are not known. The C-terminal end contains a good number of charged residues and is believed to impart solubility to the chaperone substrate complex. Due to lack of high-resolution structural data and extensive mutational work on $\alpha$-crystallin, information on the role of specific residue or groups of residues located in a given sequence region for its chaperone function is virtually non-existent.

Often there are distinctive residues or functional groups unique to the molecule or a particular region that acts as the reporting group. Tryptophan is one such reporting group in proteins, which has been extensively exploited by researchers to extract structural information of a localized region of the molecule [17,18]. Another unique reporting group present in $\alpha \mathrm{A}$-crystallin is cysteine residue that has free $-\mathrm{SH}$ group. $-\mathrm{SH}$ groups can be modified easily by a number of modifying reagents 
and those can produce very important location specific information $[19,20]$. $\alpha \mathrm{A}-\mathrm{Crystallin}$ contains two cysteine residues at positions 131 and 142, which are at the junction between the $\alpha$-crystallin domain and the C-terminal tail [5]. Since the C-terminal region is highly flexible, the accessibility of the hinge region may change if the flexibility of the C-terminal end is affected by the structural changes of $\alpha$-crystallin due to external effects or due to binding with the substrates. We tried to exploit the accessibility of the thiol groups by Ellman's reagent (DTNB) to gain information as to the involvement of the hinge region in various structural perturbations of $\alpha$-crystallin and during the binding with substrates.

\section{Materials And Methods}

\subsection{Reagents}

Urea, 2,2,2-Trifluoroethanol (TFE), L-lactate dehydrogenase (LDH) were obtained from SRL and all buffer salts, 5,5'-dithiobis-(2-nitrobenzoic acid) (DTNB) were also from SRL. Guanidine hydrochloride $(\mathrm{Gu}-\mathrm{HCl})$, Sodium dodecyl sulphate (SDS), Sodium deoxycholate, Tween-20, Carbonic anhydrase (CA), Iodoacetic acid, Adenosin triphosphate (ATP), L-cysteine were purchased from Sigma.

\subsection{Preparation of Recombinant $\alpha \mathrm{A}$ - and $\alpha \mathrm{B}$-Crystallins}

Plasmid DNA of human $\alpha \mathrm{A}$-crystallin in pAED4 vector was a gift from Dr. W. W. de Jong of Katholic University, The Netherlands. Plasmid for human $\alpha \mathrm{B}$-crystallin in pET20b+ expression vector was provided as a gift by Dr. J. Horwitz of Jules Stein Eye Institute, Los Angeles, CA, USA. For overexpression, both the plasmids were separately introduced into Escherichia coli strain BL21-DE3. Cultures were grown in LB medium at $37^{\circ} \mathrm{C}$ with IPTG induction. Cells were centrifuged, subjected to freezethaw treatment and then extracted with DNase and lysozyme. Proteins were dialyzed in $20 \mathrm{mM}$ Tris buffer, $\mathrm{pH}$ 7.2 containing $0.5 \mathrm{mM}$ EDTA and $0.5 \mathrm{mM}$ DTT (bufferA) and the precipitate removed by centrifugation. Protein solutions were concentrated in Amicon stirred cell using $100 \mathrm{kDa}$ cut off membrane. Protein solutions were applied to DEAE anion exchange column and eluted with linear $0-0.5 \mathrm{M} \mathrm{NaCl}$ gradients. Pooled $\alpha \mathrm{A}$ - and $\alpha \mathrm{B}-$ crystallin fractions were then applied to Sephacryl S-300 HR size exclusion column $(1.5 \mathrm{~cm} \times 95 \mathrm{~cm})$ and eluted with buffer-A containing $0.1 \mathrm{M} \mathrm{NaCl}$. Pooled main fractions were concentrated and dialyzed against buffer A or $50 \mathrm{mM}$ phosphate buffer $\mathrm{pH} 7.2$, containing $0.5 \mathrm{mM}$ DTT (buffer-B) and stored in aliquots at $-70^{\circ} \mathrm{C}$. SDSPAGE of both $\alpha \mathrm{A}$ - and $\alpha \mathrm{B}$-crystallin showed single band around $20 \mathrm{kDa}$. Concentration of intact recombinant proteins in solution was determined spectrophotometrically by measuring absorbance at $280 \mathrm{~nm}$ using extinction coefficients of $0.83(\mathrm{mg} / \mathrm{ml})^{-1} \cdot \mathrm{cm}^{-1}$ and 0.95 $(\mathrm{mg} / \mathrm{ml})^{-1} \cdot \mathrm{cm}^{-1}$ for $\alpha \mathrm{A}$ - and $\alpha \mathrm{B}$-crystallin respectively [21].

\subsection{Reaction of Sulphydryl Groups $(-\mathrm{SH})$ of $\alpha$ A-Crystallin with DTNB}

$\alpha \mathrm{A}$-Crystallin of $0.4 \mathrm{mg} / \mathrm{ml}$ was prepared in $50 \mathrm{mM}$ sodium phosphate containing $1 \mathrm{mM}$ EDTA buffer, $\mathrm{pH} 7.4$ and DTNB solution was added so that $\alpha \mathrm{A}$-crystallin to DTNB ratio was 1:7 (mole ratio). After adding DTNB, exposure of thiol was monitored in a Shimadzu UV2401PC spectrophotometer fitted with thermostatic cell holder assembly with electronic temperature control by measuring the absorbance at $412 \mathrm{~nm}$ at $25^{\circ} \mathrm{C}$. The kinetics of the reaction of the sulphydryl groups was studied by the double exponential equation $\mathrm{A}=\mathrm{A}_{\mathrm{o}}-\mathrm{A}_{1} \cdot \exp$ $\left(-\mathrm{k}_{1} \cdot \mathrm{x}\right)-\mathrm{A}_{2} \cdot \exp \left(-\mathrm{k}_{2} \cdot \mathrm{x}\right)$, where $\mathrm{k}_{1}$ and $\mathrm{k}_{2}$ are rate constants.

\subsection{DTNB Kinetics with $\alpha \mathrm{A}$-Crystallin in Different Reagents}

Same experiment with DTNB was performed by using different reagent like urea, $\mathrm{Gu}-\mathrm{HCl}, \mathrm{SDS}$, sodium deoxycholate, Tween-20 and organic solvent like TFE where concentration of $\alpha \mathrm{A}$-crystallin was same i.e. 0.4 $\mathrm{mg} / \mathrm{ml}$ in all of the reagents. Individual solutions of $\alpha \mathrm{A}$-crystallin were incubated in $1 \mathrm{M}, 1.5 \mathrm{M}, 2 \mathrm{M}, 2.5 \mathrm{M}$, $3 \mathrm{M}$ and $4 \mathrm{M}$ urea in $50 \mathrm{mM}$ sodium phosphate containing $1 \mathrm{mM}$ EDTA buffer, $\mathrm{pH} 7.4$ for 18 hours. DTNB was added to maintain the same ratio and absorbance was measured at $412 \mathrm{~nm}$ as a function of time. $\alpha \mathrm{A}$-Crystallin of same concentration was prepared in $4 \mathrm{M} \mathrm{Gu}-\mathrm{HCl}$ in same buffer and incubated for 18 hours to see the effect of DTNB as before.

$\alpha \mathrm{A}-$ Crystallin was incubated in $0.5 \mathrm{mM}, 1 \mathrm{mM}$ and 2 $\mathrm{mM}$ SDS in $10 \mathrm{mM}$ sodium phosphate buffer, 7.5; in 2 $\mathrm{mM}$ Tween-20 in same buffer; in 1\% sodium deoxycholate in $10 \mathrm{mM}$ sodium phosphate buffer, $\mathrm{pH} 7.9$ for 1 hour. In organic solvent like $0.1 \%, 1 \%$ and $30 \%$ TFE, $\alpha \mathrm{A}$-crystallin was incubated for 1 hour. In all these solutions, DTNB was added at the same ratio for measuring the absorbance at $412 \mathrm{~nm}$.

\subsection{DTNB Kinetics with $\alpha \mathrm{A}$-Crystallin in Different Reagents-Effect of Varying Incubation Time}

To see whether there is any change in thiol exposure with varying incubation time in different reagents, we incubated individual solutions of $\alpha \mathrm{A}$-crystallin in 0.5 $\mathrm{mM}$ and $2 \mathrm{mM}$ SDS for different time. Same method was 
followed for $1 \%$ deoxycholate, $2 \mathrm{mM}$ Tween-20 and $30 \%$ TFE.

In case of $4 \mathrm{M}$ urea and $4 \mathrm{M} \mathrm{Gu}-\mathrm{HCl}$, two solutions were prepared for each reagent; one was solution of 1 hour incubation and other was 18 hours incubation to see the effect.

One experiment was done where $\alpha \mathrm{A}$-crystallin was incubated with $2 \mathrm{mM}$ SDS for 18 hours. Then the solution was dialyzed with $10 \mathrm{mM}$ sodium phosphate buffer, pH 7.5 to remove SDS and DTNB was added for measuring the absorbance at $412 \mathrm{~nm}$.

\subsection{Blocking of Sulphydryl Groups of LDH}

For blocking of sulphydryl groups of LDH, iodoacetic acid solution was added to $\mathrm{LDH}$ solution in $50 \mathrm{mM}$ sodium phosphate buffer containing $1 \mathrm{M} \mathrm{Gu}-\mathrm{HCl}, \mathrm{pH} 8.0$ so that the final concentration of LDH was $1 \mathrm{mg} / \mathrm{ml}$ and iodoacetic acid was $10 \mathrm{mM}$. Reaction was continued for 6.5 hours and then the solution was dialyzed by $50 \mathrm{mM}$ sodium phosphate buffer containing $0.1 \mathrm{M} \mathrm{NaCl}$ and 1 $\mathrm{mM}$ EDTA, $\mathrm{pH} 7.4$, to remove iodoacetic acid. To see whether the blocking of thiol was complete, urea was added to the solution to make urea concentration $6 \mathrm{M}$ and then DTNB was added. By measuring the absorbance at $412 \mathrm{~nm}$, it was seen that no significant absorbance value was obtained meaning that thiols of $\mathrm{LDH}$ were blocked. CA has no thiol. So reaction with iodoacetic acid was not required.

\subsection{DTNB Kinetics with $\alpha \mathrm{A}$-Crystallin after Binding with Substrate}

$\mathrm{LDH}$ and $\mathrm{CA}$ were chosen as substrate for $\alpha \mathrm{A}$-crystallin. LDH (after blocking of thiol) and CA solutions were prepared and in both of these solutions $\alpha \mathrm{A}$-crystallin solution was added where substrate concentration became $0.2 \mathrm{mg} / \mathrm{ml}$ and $\alpha \mathrm{A}$-crystallin $0.3 \mathrm{mg} / \mathrm{ml}$ i.e. $\alpha \mathrm{A}$ crystallin to substrate ratio was $2: 1$ (mole ratio). Another solution of only $\alpha \mathrm{A}$-crystallin without substrate of 0.3 $\mathrm{mg} / \mathrm{ml}$ was prepared as control. These three solutions were heated at $65^{\circ} \mathrm{C}$ for 1 hour and cooled for 1 hour. Then these solutions were centrifuged at 10,000 rpm and in supernatant DTNB was added so that $\alpha \mathrm{A}$-crystallin to DTNB ratio was 1:8.

ATP was used for binding with $\alpha$ A-crystallin where final concentration of ATP was $3 \mathrm{mM}$ and $5 \mathrm{mM}$ after incubation with $\alpha \mathrm{A}$-crystallin for 1 hour.

\subsection{DTNB Kinetics with $\alpha$ A-Crystallin Mixed with $\alpha \mathrm{B}-$ Crystallin}

$\alpha \mathrm{A}$ - and $\alpha \mathrm{B}-\mathrm{Crystallin}$ were mixed in 3:1 ratio and incubated at $25^{\circ} \mathrm{C}, 37^{\circ} \mathrm{C}$ and $60^{\circ} \mathrm{C}$ for 1 hour and cooled for 1 hour. Also, one solution was prepared where $\alpha \mathrm{A}$ - and $\alpha \mathrm{B}$-crystallin were mixed in 1:1 ratio and heated at $60^{\circ} \mathrm{C}$ for 1 hour and cooled for 1 hour. With these solutions DTNB kinetics was performed.

\section{9. $\alpha$ A-Crystallin Pre-Incubated at Different Temperatures}

$\alpha \mathrm{A}$-Crystallin was incubated at different temperatures i.e., $37^{\circ} \mathrm{C}, 45^{\circ} \mathrm{C}, 60^{\circ} \mathrm{C}, 70^{\circ} \mathrm{C}$ for 1 hour and cooled for 1 hour for seeing the effect of DTNB.

\subsection{Reaction of Thiol of $L-C y s t e i n e$ with DTNB}

Solution of L-cysteine of $40 \mu \mathrm{M}$ (as in $\alpha$ A-crystallin) was prepared in $4 \mathrm{M}$ urea, $1 \mathrm{mM}$ SDS, $2 \mathrm{mM}$ Tween-20, $30 \%$ TFE in water, $\mathrm{pH} 4$. Two individual solutions of L-cysteine were prepared in each reagent-one was incubated for 5 minutes and other was for 18 hour. One solution of L-cysteine of $40 \mu \mathrm{M}$ was prepared without any reagent. To these solutions DTNB was added and absorbance at $412 \mathrm{~nm}$ was measured as in $\alpha \mathrm{A}$-crystallin.

\subsection{Partial Blocking of Thiol Group of $\alpha$ A-Crystallin and DTNB Kinetics with That $\alpha \mathrm{A}$-Crystallin in Urea and SDS}

For blocking of one thiol group (which is at position 142) of $\alpha \mathrm{A}$-crystallin, iodoacetic acid solution was added to $\alpha \mathrm{A}$-crystallin solution in $50 \mathrm{mM}$ sodium phosphate buffer, $\mathrm{pH} 8.0$ so that the final concentration of $\alpha \mathrm{A}$ crystallin was $0.5 \mathrm{mg} / \mathrm{ml}$ and iodoacetic acid was $2 \mathrm{mM}$. Reaction was continued for 1.5 hours and the dialysis of the solution was done by $50 \mathrm{mM}$ sodium phosphate buffer containing $0.1 \mathrm{M} \mathrm{NaCl}$ and $1 \mathrm{mM}$ EDTA, $\mathrm{pH} 7.4$, to remove iodoacetic acid. To see whether the blocking of one thiol was complete, urea was added to the solution to make urea concentration $6 \mathrm{M}$ and then DTNB was added. By measuring the absorbance at $412 \mathrm{~nm}$, it was observed that one thiol of $\alpha \mathrm{A}$-crystallin was blocked.

After blocking of one thiol of $\alpha \mathrm{A}$-crystallin, DTNB kinetics was performed in urea of concentration $1 \mathrm{M}, 2$ $\mathrm{M}, 3 \mathrm{M}$ and SDS of $0.1 \mathrm{mM}, 0.3 \mathrm{mM}$ as done before.

\section{RESULTS}

The reactivity of the two sulphydryl groups in $\alpha \mathrm{A}$-crystallin was followed by monitoring the kinetics of the DTNB reaction whose product has an absorbance at 412 $\mathrm{nm}\left(\mathrm{A}_{412}\right)$. When native $\alpha \mathrm{A}$-crystallin was reacted with DTNB, the kinetic profile (trace 1, Figure 1) showed rapid increase in $\mathrm{A}_{412}$ up to about 20 minutes after which it leveled off. The increase in $\mathrm{A}_{412}$ during the first 20 minutes was shown in the inset of Figure 1. The saturation value of $\mathrm{A}_{412}$ obtained at 8 hours for native protein roughly corresponded to $\sim 0.9-\mathrm{SH}$ modified by DTNB per subunit of $\alpha \mathrm{A}$-crystallin indicating that out of 


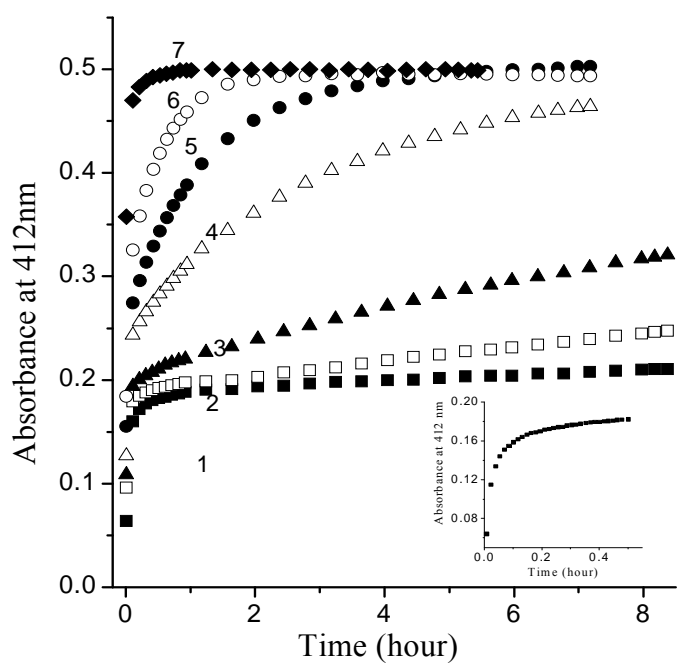

Figure 1. DTNB kinetic profiles of $\alpha \mathrm{A}$-crystallin at various concentration of urea. $\alpha \mathrm{A}$-Crystallin concentration was $0.4 \mathrm{mg} / \mathrm{ml}$, in $50 \mathrm{mM}$ sodium phosphate buffer containing $1 \mathrm{mM}$ EDTA, pH 7.4 and DTNB in 6 -fold molar excess over the protein. Absorbance was measured at $412 \mathrm{~nm}$ as a function of time. (1) no urea, (2) $1 \mathrm{M}$ urea, (3) $1.5 \mathrm{M}$ urea, (4) $2 \mathrm{M}$ urea, (5) $2.5 \mathrm{M}$ urea, (6) $3 \mathrm{M}$ urea and (7) $4 \mathrm{M}$ urea. All the solutions were incubated for 18 hours. Inset shows the same data for no urea in expanded axes.

the two, one was totally unavailable and the other was nearly fully available.

In order to increase the availability of the thiol residues by loosening the $\alpha$-crystallin structure, urea was added prior to DTNB reaction. At $1 \mathrm{M}$ urea, the region of rapid increase in $\mathrm{A}_{412}$ was same as that of native $\alpha \mathrm{A}$-crystallin but after $\sim 20$ minutes a slow but steady increase in $\mathrm{A}_{412}$ was observed (trace 2) in contrast to a nearly flat profile observed for the native $\alpha \mathrm{A}$-crystallin. At $1.5 \mathrm{M}$ urea, the slope of the final part of the kinetic further increased, but no saturation was observed up to 8 hours (trace 3). At $2 \mathrm{M}$ urea, $\mathrm{A}_{412}$ reached over 0.45 (trace 4), still showing no saturation within 8 hours. Saturation however was reached in 5 hours at $2.5 \mathrm{M}$ urea with limiting $\mathrm{A}_{412}$ at 0.5 (trace 5). At $3 \mathrm{M}$ and $4 \mathrm{M}$ urea, the limiting $\mathrm{A}_{412}$ remained constant at 0.5 but the time to reach the saturation decreased to 1.5 hours and 0.5 hour respectively (trace 6 and 7). This limiting $A_{412}$ value of 0.5 corresponded to two $-\mathrm{SH}$ groups being accessible in $\alpha \mathrm{A}$-crystallin. Both the $-\mathrm{SH}$ groups can be made accessible to DTNB by partial denaturation of $\alpha \mathrm{A}$-crystallin at or over $2.5 \mathrm{M}$ urea.

There are other chemicals that can also denature $\alpha$-crystallin. Anionic surfactant SDS has often been used to induce protein denaturation, although a bit differently instead of promoting flexible random coil structure as in the case of urea, SDS promotes helical structure [22]. The effect of various concentrations of SDS on the ac- cessibility of the thiol residues of $\alpha \mathrm{A}$-crystallin was shown in Figure 2(A). In absence of SDS, only one $-\mathrm{SH}$ group reacted per subunit of $\alpha \mathrm{A}$-crystallin and a near saturation in the reaction level was obtained in about 1 hour (trace 1). In presence of $0.5 \mathrm{mM}$ SDS a big jump in thiol reactivity in 2 hours was observed (trace 2). At 1 $\mathrm{mM}$ SDS, the saturation level was attained within 10 minutes. The $\mathrm{A}_{412}$ obtained at $1 \mathrm{mM}$ SDS roughly corresponded to $2-\mathrm{SH}$ per $\alpha \mathrm{A}$-crystallin subunit. Interestingly a decrease in $\mathrm{A}_{412}$ was observed when SDS concentration was increased to $2 \mathrm{mM}$. In order to understand the effect of SDS on the thiol reactivity of $\alpha \mathrm{A}$-crystallin we incubated $\alpha \mathrm{A}$-crystallin with $0.5 \mathrm{mM}$ and $2 \mathrm{mM}$ SDS for various lengths of time and then measured the thiol reactivity. The results were presented in Figures 2(B) and $(\mathbf{C})$ respectively. In both the cases with increase in incubation time, thiol reactivity progressively diminished and after 18 hours of incubation no thiol was available for reaction with DTNB.

Since the results with the anionic detergents were interesting, we also studied the effect of a milder anionic detergent Na-deoxycholate (Figures 3(A) and (B)) and a non-toxic detergent Tween-20 (Figure 3(C)) on the thiol reactivity. In $1 \% \mathrm{Na}$-deoxycholate an increase in thiol group accessibility over that in its absence was observed (Figure 3(A)). In this case also, the accessibility decreased with increase in time of incubation with $1 \%$ Na-deoxycholate (Figure 3(B)). In presence of $2 \mathrm{mM}$ Tween-20, an increase in $\mathrm{A}_{412}$ was observed till 30 minutes followed by a decrease thereafter (Figure 3(C)).

We also studied the effect of TFE, a helix promoting agent in proteins on the thiol reactivity of $\alpha \mathrm{A}$-crystallin (Figures 4(A) and (B)). As little as 0.1\% TFE moderately enhanced the thiol reactivity. A significant rise in reactivity was observed when $30 \%$ TFE was used (Figure 4(A)). Saturation in $A_{412}$ was reached within 15 minutes of start of the DTNB reaction and there was nearly two fold increase in $\mathrm{A}_{412}$ in $30 \%$ TFE compared to that in its absence. Again, in this case also thiol accessibility decreased as $\alpha \mathrm{A}$-crystallin was incubated with TFE for increasing length of the time (Figure 4(B)) and in 18 hours, almost no reaction could be observed.

The effect of ATP on the structure and function of $\alpha$-crystallin has been studied by many researchers [23-27]. Recent studies have shown that ATP stabilizes the structure of $\alpha$-crystallin by making it more compact and protease cleavage resistant [28-30]. Eye lens has one of the highest ATP concentrations known in living tissue. We have therefore studied the effect of ATP on the accessibility of the thiols in $\alpha \mathrm{A}$-crystallin (Figure 4(C)). It was seen that there was a slight reduction in the final $\mathrm{A}_{412}$ obtained in presence of $3 \mathrm{mM}$ ATP compared to that in its absence. The kinetic profile at $5 \mathrm{mM}$ ATP remained same as that at $3 \mathrm{mM}$ ATP. The initial steep rise in $\mathrm{A}_{412}$ 

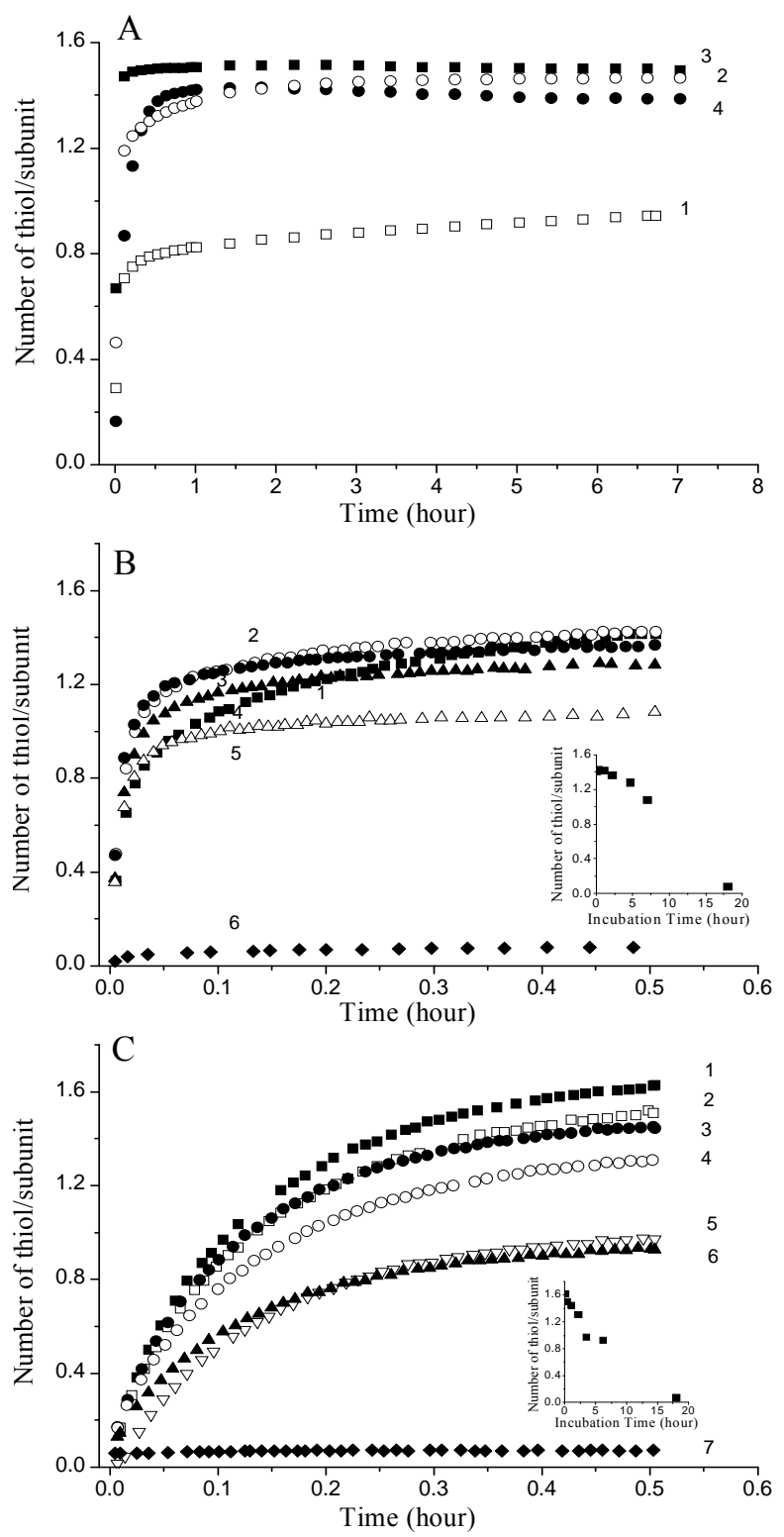

Figure 2. (A) Kinetic measurement of thiol reactivity of $\alpha \mathrm{A}$ crystallin in different concentration of SDS. $\alpha \mathrm{A}$-Crystallin was $0.4 \mathrm{mg} / \mathrm{ml}$ in $10 \mathrm{mM}$ sodium phosphate buffer, $\mathrm{pH} 7.5$, DTNB in 6-fold molar excess over the protein. (1) no SDS, (2) $0.5 \mathrm{mM}$ SDS, (3) $1 \mathrm{mM}$ SDS and (4) $2 \mathrm{mM}$ SDS. Absorbance at $412 \mathrm{~nm}$ was converted into number of thiol/subunit by using extinction coefficient $13600 \mathrm{M}^{-1} \cdot \mathrm{cm}^{-1}$. Incubation time for all the solutions was $1 \mathrm{~h}$. (B) DTNB kinetic profiles of $\alpha \mathrm{A}$-crystallin in 0.5 mM SDS varying incubation time. (1) $3 \mathrm{~min}$, (2) $1 \mathrm{~h}$, (3) $2 \mathrm{~h}$, (4) $4.5 \mathrm{~h},(5) 7 \mathrm{~h}$ and (6) $18 \mathrm{~h}$. Inset shows the plot of number of thiol/subunit (at 30 minutes of incubation for each solution) against incubation time. $\alpha$ A-Crystallin was $0.4 \mathrm{mg} / \mathrm{ml}$ in 10 $\mathrm{mM}$ sodium phosphate buffer, $\mathrm{pH} 7.5$ and DTNB in 6-fold molar excess over the protein. (C) Kinetics of DTNB reaction with $\alpha \mathrm{A}$-crystallin in $2 \mathrm{mM}$ SDS varying incubation time. (1) 1 min, (2) $15 \mathrm{~min}$, (3) $1 \mathrm{~h}$, (4) $2 \mathrm{~h}$, (5) $3.5 \mathrm{~h}$, (6) $6 \mathrm{~h}$ and (7) $18 \mathrm{~h}$. $\alpha \mathrm{A}$-Crystallin and DTNB concentration were same as in (B). Inset shows the plot of number of thiol/subunit (at 30 minutes of incubation for each solution) against incubation time.
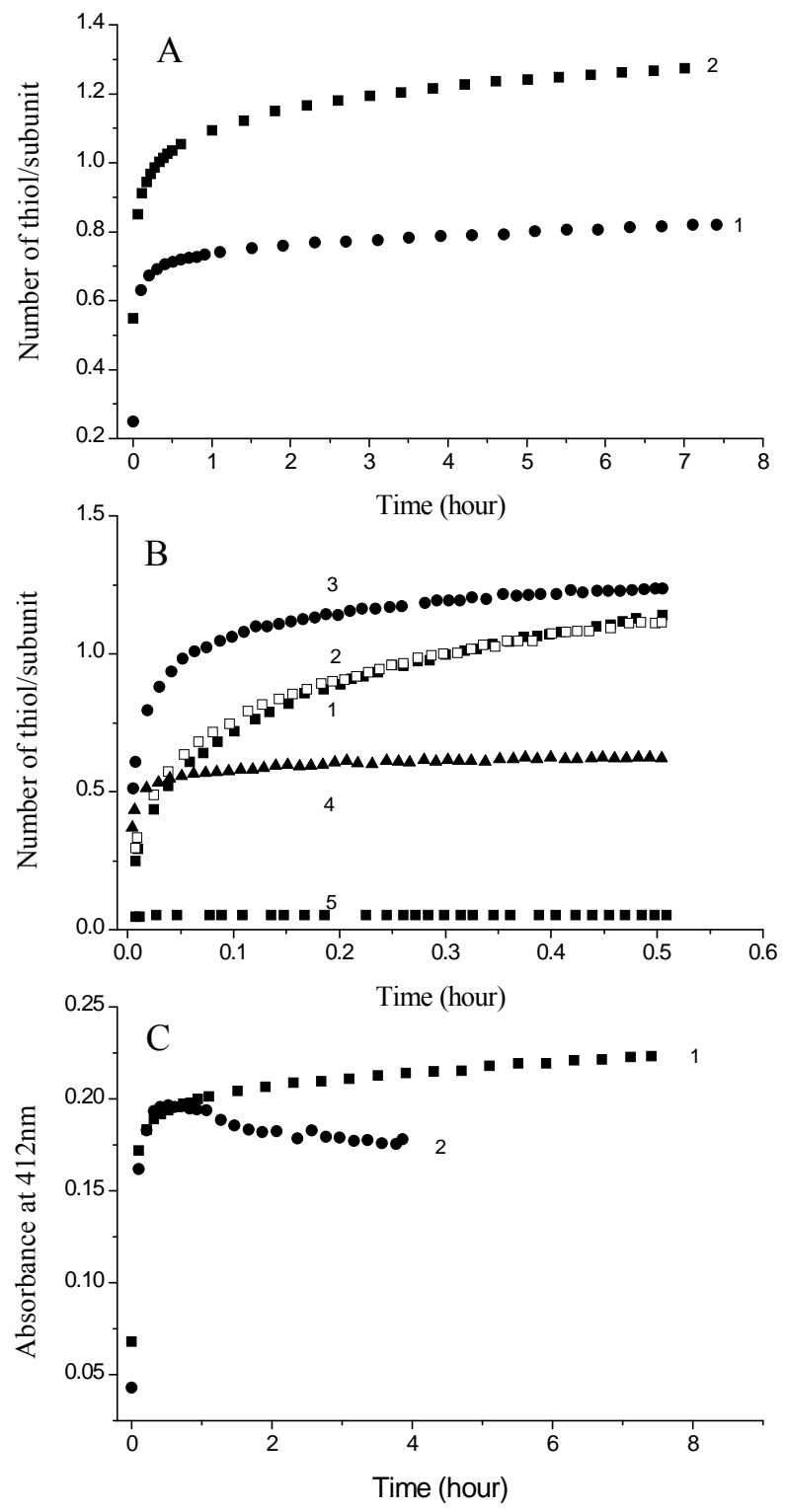

Figure 3. (A) Knetics of DTNB reaction with $\alpha$ A-crystallin in $1 \%$ sodium deoxycholate. (1) in absence of $1 \%$ sodium deoxycholate and (2) in presence of $1 \%$ sodium deoxycholate and incubated for $1 \mathrm{~h}$. (B) Knetics of DTNB reaction with $\alpha \mathrm{A}$ crystallin in $1 \%$ sodium deoxycholate varying incubation time (1) $8 \mathrm{~min}$, (2) $30 \mathrm{~min}$, (3) $1 \mathrm{~h}$, (4) $4.5 \mathrm{~h}$ and (5) $18 \mathrm{~h} . \alpha \mathrm{A}$-Crystallin concentration was $0.4 \mathrm{mg} / \mathrm{ml}$ in $10 \mathrm{mM}$ sodium phosphate buffer, $\mathrm{pH} 7.9$, DTNB in 6-fold molar excess over the protein. Absorbance was measured at $412 \mathrm{~nm}$ as a function of time. (C) Kinetic measurement of thiol reactivity of $\alpha \mathrm{A}$-crystallin in $2 \mathrm{mM}$ Tween-20. Absorbance measured at $412 \mathrm{~nm}$ as a function of time. $\alpha$ A-Crystallin was $0.4 \mathrm{mg} / \mathrm{ml}$ in $10 \mathrm{mM}$ sodium phosphate buffer $\mathrm{pH} 7.5$, DTNB in 6-fold molar excess over the protein. (1) In absence of $2 \mathrm{mM}$ Tween-20 and (2) in presence of $2 \mathrm{mM}$ Tween-20 and incubated for $1 \mathrm{~h}$.

during the first 15 minutes remained unchanged, only the later part became flat in presence of ATP.

In Figure 5, we studied the effect of pre-incubation 

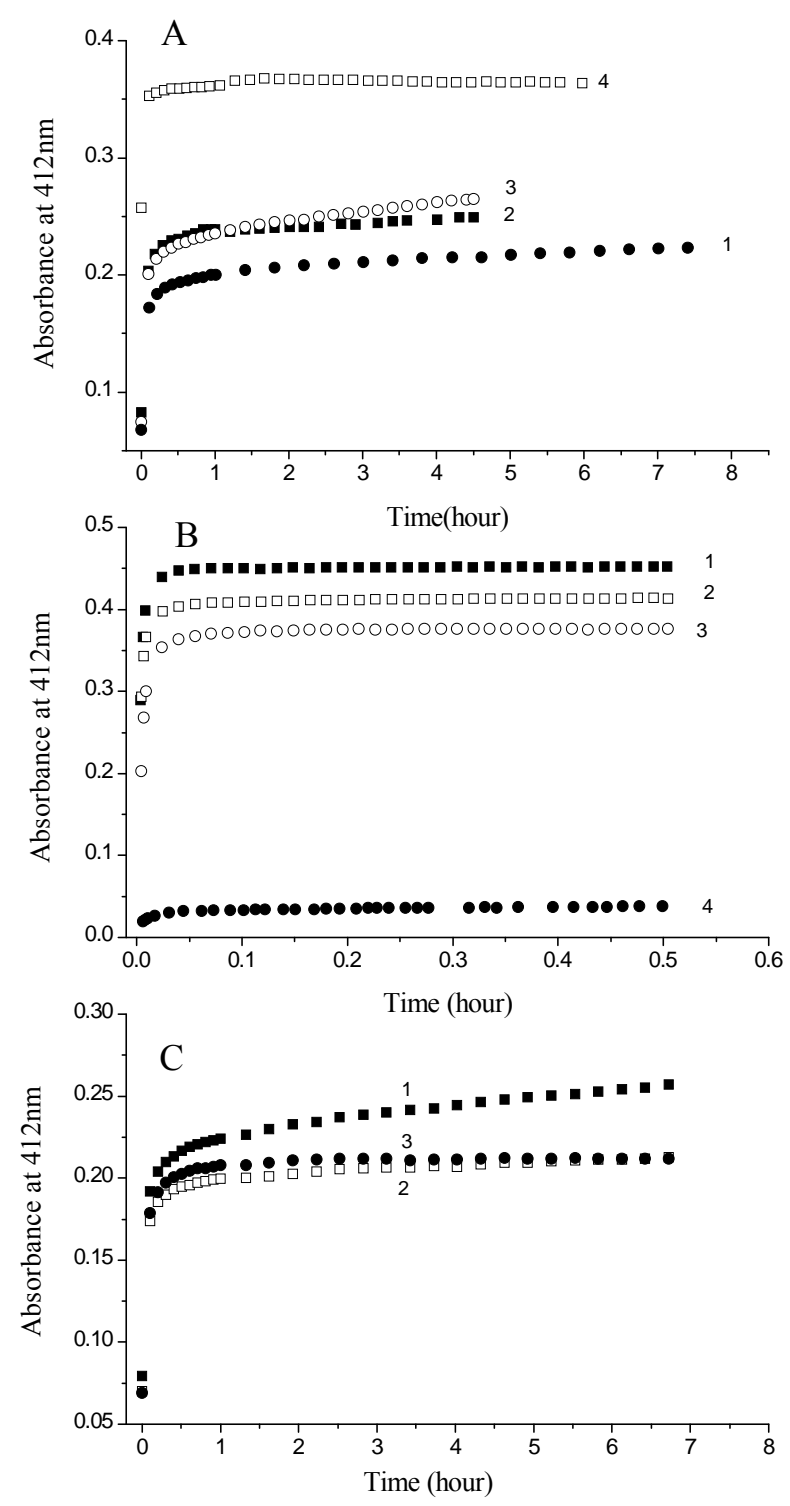

Figure 4. (A) Kinetics of DTNB reaction with $\alpha \mathrm{A}$-crystallin in presence of TFE. (1) no TFE, (2) $0.1 \%$ TFE, (3) $1 \%$ TFE and (4) $30 \%$ TFE. Incubation time for all the solutions was $1 \mathrm{~h} . \alpha \mathrm{A}-$ Crystallin concentration was $0.4 \mathrm{mg} / \mathrm{ml}$, DTNB in 6-fold molar excess over the protein. Absorbance was measured at $412 \mathrm{~nm}$ as a function of time. (B) Kinetics of DTNB reaction with $\alpha \mathrm{A}$-crystallin in presence of TFE varying incubation time. (1) 6 min, (2) $30 \mathrm{~min}$, (3) $1 \mathrm{~h}$ and (4) $18 \mathrm{~h}$. $\alpha \mathrm{A}$-Crystallin concentration was $0.4 \mathrm{mg} / \mathrm{ml}$, DTNB in 6-fold molar excess over the protein. (C) Kinetic measurement of thiol reactivity of of $\alpha \mathrm{A}$ crystallin in presence and in absence of ATP. $\alpha$ A-Crystallin was $0.4 \mathrm{mg} / \mathrm{ml}$, DTNB in 6-fold molar excess over the protein. (1) no ATP, (2) $3 \mathrm{mM}$ ATP and (3) $5 \mathrm{mM}$ ATP.

temperature on the reactivity of the thiols of $\alpha \mathrm{A}$-crystallin. There was a very slight increase in the flatter part of the kinetic profile as incubation temperature increased from $25^{\circ} \mathrm{C}$ to $45^{\circ} \mathrm{C}$. At $60^{\circ} \mathrm{C}$, there was a moderate increase which remained unchanged as pre-incubation

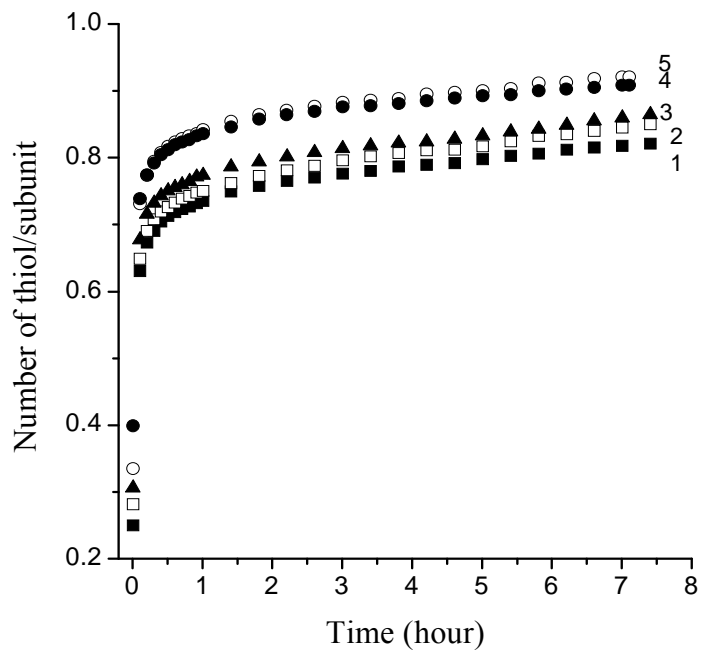

Figure 5. Measurement of absorbance at $412 \mathrm{~nm}$ as a function of time of $\alpha \mathrm{A}$-crystallin pre-incubated at various temperature where pre-incubation temperature were (1) $25^{\circ} \mathrm{C}$, (2) $37^{\circ} \mathrm{C}$, (3) $45^{\circ} \mathrm{C}$, (4) $60^{\circ} \mathrm{C}$, (5) $70^{\circ} \mathrm{C}$. All the solutions were incubated at different temperature for 45 min and cooled for $1 \mathrm{~h}$. $\alpha \mathrm{A}$-Crystallin concentration was $0.4 \mathrm{mg} / \mathrm{ml}$, DTNB in 6 -fold molar excess over the protein.

temperature was increased to $70^{\circ} \mathrm{C}$. The $\mathrm{A}_{412}$ values obtained in this set of data indicates only one thiol was accessible, only the rate of accessibility was enhanced with increase of pre-incubation temperature.

In the lens, $\alpha \mathrm{A}$ - and $\alpha \mathrm{B}$-crystallin remain together in complexed form in $3: 1$ ratio. $\alpha \mathrm{B}$-Crystallin has two disulphide bonds and has no free $-\mathrm{SH}$ group and hence does not react with DTNB unless the disulphides are reduced. We have studied the effect of addition of $\alpha \mathrm{B}$ crystallin on the thiol reactivity of $\alpha \mathrm{A}$-crystallin (Figure 6(A)). When $\alpha \mathrm{B}$-crystallin was added to $\alpha \mathrm{A}$-crystallin at $3: 1 \mathrm{w} / \mathrm{w}$ ratio and the mixture was pre-incubated at $25^{\circ} \mathrm{C}$ or $37^{\circ} \mathrm{C}$, the reaction kinetic profile remained same as that for $\alpha \mathrm{A}$-crystallin alone pre-incubated at these temperatures (as shown in Figure 5). When the 3:1 mixture of $\alpha \mathrm{A}$ - and $\alpha \mathrm{B}$-crystallin was pre-incubated at $60^{\circ} \mathrm{C}$, the reactivity enhanced compared to $\alpha \mathrm{A}$-crystallin alone preincubated at the same temperature. The absorbance value at 8 hours corresponds to $\sim 1.25-\mathrm{SH}$ reacted per subunit of $\alpha \mathrm{A}$-crystallin. However when a 1:1 mixture of $\alpha \mathrm{A}$ and $\alpha \mathrm{B}$-crystallin was heat pre-treated at $60^{\circ} \mathrm{C}$, the slow phase of the reaction after first 30 minutes was not observed, as absorbance reached limiting value which corresponded roughly to one $-\mathrm{SH}$ reacted per subunit of $\alpha \mathrm{A}$-crystallin (data not shown). In other words, addition of equimolar concentration of $\alpha \mathrm{B}$-crystallin made the second thiol of $\alpha \mathrm{A}$-crystallin completely unavailable, while addition at 3:1 ratio between $\alpha \mathrm{A}$ - and $\alpha \mathrm{B}$-crystallin made the second thiol only marginally $(\sim 25 \%)$ available. 


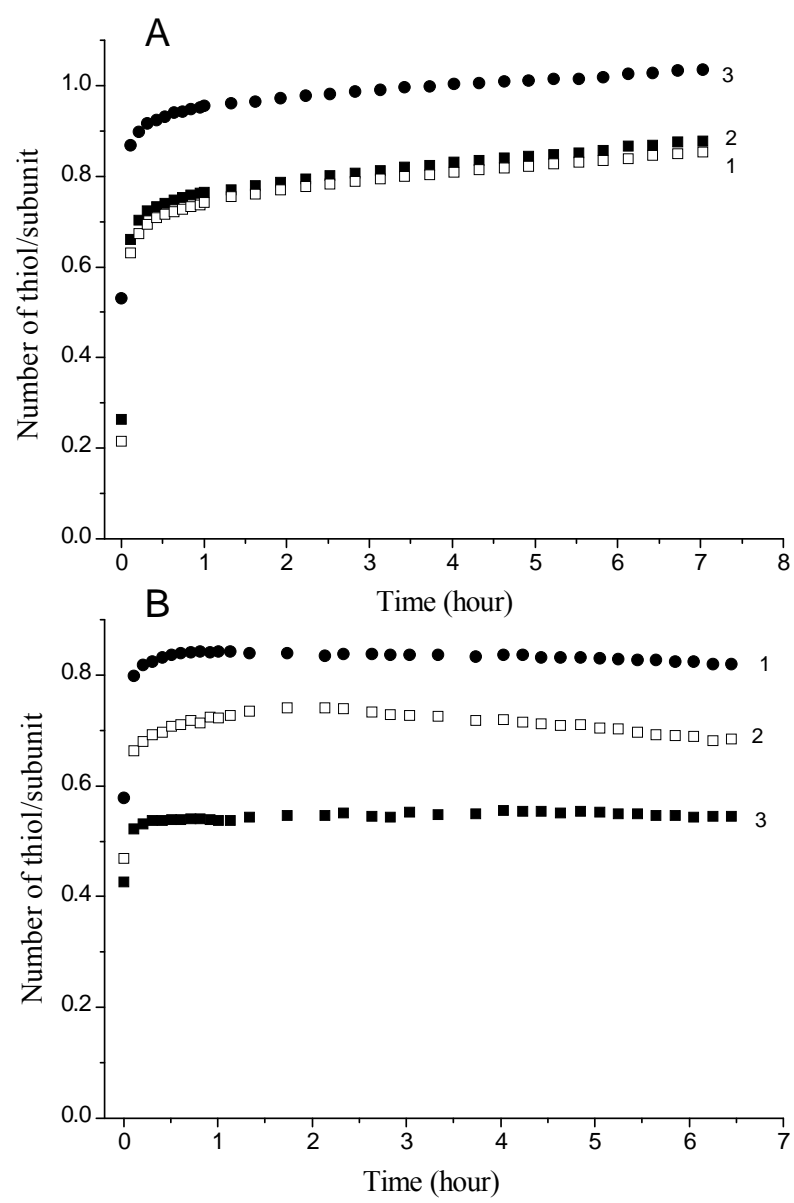

Figure 6. (A) Kinetics of DTNB reaction with $\alpha$ A-crystallin mixed with $\alpha \mathrm{B}$-crystallin in various proportions. (1) $\alpha \mathrm{A}-+\alpha \mathrm{B}-$ crystallin at $3: 1$ and pre-incubated at $25^{\circ} \mathrm{C}$, (2) $\alpha \mathrm{A}-+\alpha \mathrm{B}$ crystallin at $3: 1$ andpre-incubated at $37^{\circ} \mathrm{C}$, (3) $\alpha \mathrm{A}-+\alpha \mathrm{B}$-crystallin at $3: 1$ and pre-incubated at $60^{\circ} \mathrm{C}$. All the samples were incubated at respective temperature for $1 \mathrm{~h}$ and cooled for $1 \mathrm{~h}$. $\alpha \mathrm{A}$-Crystallin was $0.4 \mathrm{mg} / \mathrm{ml}$, DTNB in 6-fold molar excess over the protein. Absorbance was measured at $412 \mathrm{~nm}$ as a function of time. (B) Kinetic measurement of reactivity of thiols of $\alpha \mathrm{A}$-crystallin complexed with substrate. (1) $\alpha \mathrm{A}$-crystallin pre-incubated at $65^{\circ} \mathrm{C}$, (2) $\alpha \mathrm{A}$-crystallin complexed with $\mathrm{LDH}$ and pre-incubated at $65^{\circ} \mathrm{C}$ and (3) $\alpha \mathrm{A}$-crystallin complexed with $\mathrm{CA}$ and pre-incubated at $65^{\circ} \mathrm{C}$. $\alpha \mathrm{A}$-Crystallin concentration was $0.3 \mathrm{mg} / \mathrm{ml}$ and $\alpha \mathrm{A}$-crystallin to substrate ratio $2: 1$ (mole ratio). $\alpha \mathrm{A}$-Crystallin to DTNB ratio was $1: 8$. Absorbance was measured at $412 \mathrm{~nm}$ as a function of time. All the solutions were heated at $65^{\circ} \mathrm{C}$ for $1 \mathrm{~h}$ and cooled for $1 \mathrm{~h}$.

To see the effect of bound substrate on the accessibility of the thiol groups of $\alpha \mathrm{A}$-crystallin, we have chosen two substrates namely carbonic anhydrase (CA) and lactate dehydrogenase (LDH). CA does not have any free $-\mathrm{SH}$ group and hence would least interfere with the measurement procedure and data analysis. Free thiols of LDH were blocked completely by iodoacetic acid treatment and the unavailability of any free $-\mathrm{SH}$ of iodoacetic acid blocked LDH was checked by DTNB modification (data not shown). Complexes between $\alpha \mathrm{A}$-crystallin and its substrates were formed by incubating the mixture at $2: 1(\mathrm{w} / \mathrm{w})$ ratio at $65^{\circ} \mathrm{C}$. The complexes were cooled back to $25^{\circ} \mathrm{C}$ before DTNB kinetics experiment, the results of which were presented in Figure $6(B)$. The results showed that accessibility of thiol was decreased when $\alpha \mathrm{A}$-crystallin was complexed with $\mathrm{LDH}$ or CA. The decrease was more in case of CA than $\mathrm{LDH}$.

To see the effect of DTNB on cys-131, the fast reacting cys-142 was blocked. After blocking, the effect of 0.1 $\mathrm{mM}$ and $0.3 \mathrm{mM}$ SDS on the said thiol was observed. In presence of $0.1 \mathrm{mM}$ SDS, saturation in $\mathrm{A}_{412}$ was not reached even after 3 hours (Figure $7(\mathbf{A})$ ). At $0.3 \mathrm{mM}$ SDS, the saturation level was attained before 1 hour
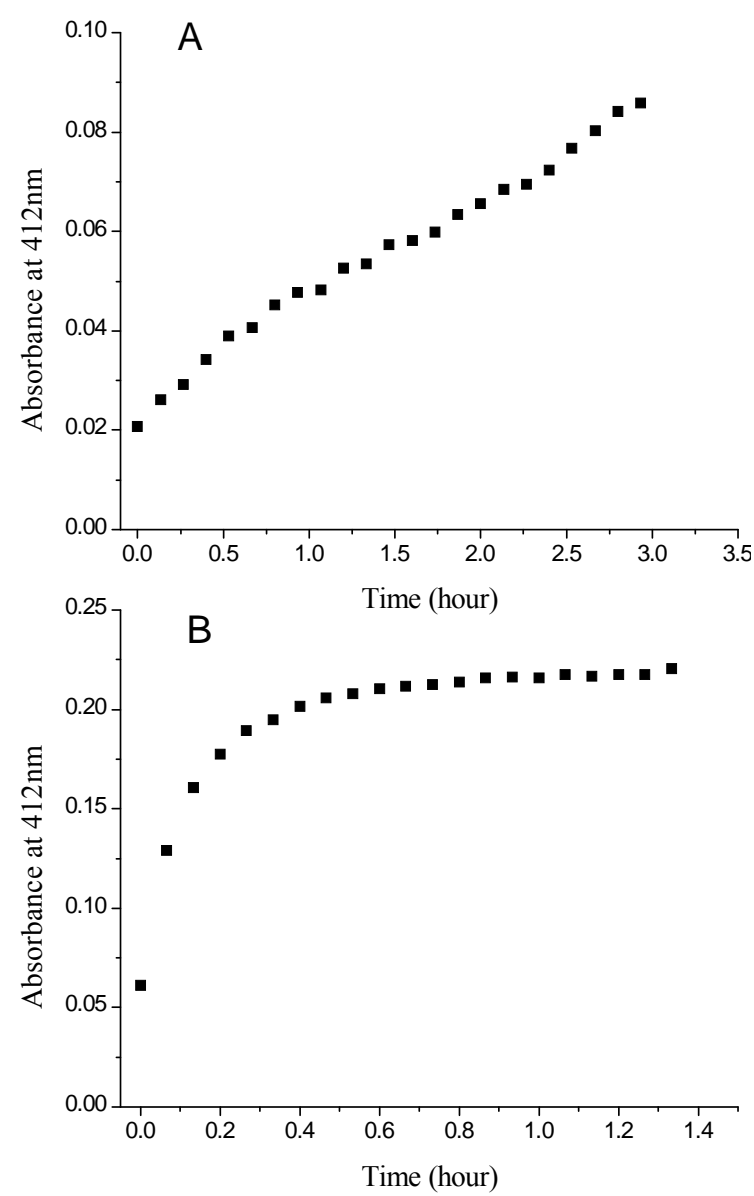

Figure 7. (A) Kinetic measurement of reactivity of cys-131 of $\alpha$ A-crystallin in $0.1 \mathrm{mM} \mathrm{SDS}$, when cys- 142 was blocked. $\alpha \mathrm{A}-$ Crystallin was $0.4 \mathrm{mg} / \mathrm{ml}$ in $10 \mathrm{mM}$ sodium phosphate buffer, $\mathrm{pH} 7.5$, DTNB in 6-fold molar excess over the protein. Absorbance was measured at $412 \mathrm{~nm}$ as a function of time. Incubation time for the solution with $0.1 \mathrm{mM}$ SDS was $1 \mathrm{~h}$. (B) Kinetic measurement of reactivity of cys-131 of $\alpha \mathrm{A}$-crystallin in $0.3 \mathrm{mM}$ SDS, when cys-142 was blocked. $\alpha \mathrm{A}-$ Crystallin was $0.4 \mathrm{mg} / \mathrm{ml}$ in $10 \mathrm{mM}$ sodium phosphate buffer, $\mathrm{pH} 7.5$, DTNB in 6-fold molar excess over the protein. Absorbance was measured at $412 \mathrm{~nm}$ as a function of time. Incubation time for the solution with $0.1 \mathrm{mM}$ SDS was $1 \mathrm{~h}$. 
(Figure 7(B)). The effect of urea on cys-131 was also observed. At $1 \mathrm{M}$ urea, $\mathrm{A}_{412}$ was gradually increasing and saturation was not attained after 4 hours (Figure 8(A)). On the other hand, at $2 \mathrm{M}$ urea, saturation was reached within 1 hour (Figure 8(B)) and at $3 \mathrm{M}$ urea, within few minutes (Figure 8(C)).

\section{DISCUSSION}

The A-chain of human $\alpha$-crystallin contains two cysteine residues one at position 131 and the other at position 142 and in the lens they remain without forming any disulphide bridge. The B-chain does not contain any cysteine residues in its sequence. Thus only $\alpha \mathrm{A}$-crystallin contains free $-\mathrm{SH}$ groups that can be modified by DTNB. It has already been reported that of the two cysteines, the one at position 142 was fully exposed while the one at position 131 was buried [31]. The kinetic profile obtained for native $\alpha \mathrm{A}$-crystallin (Figure 1) clearly showed that the surface exposed thiol reacted quickly in about first 30 minutes while the second thiol continued to react slowly even after 8 hours. Early work by Siezen et al. [32] reported three classes of sulphydryl groups in bovine $\alpha$-crystallin based on their reactivity with DTNB. According to them, Class I thiol groups were surface exposed, Class II thiols were in hydrophobic environment and were accessible to hydrophobic reagents only and the Class III thiols were completely inaccessible. In our study with recombinant preparation, we distinctly see two kinds of thiols, one that reacted fast and the other relatively slow in native condition. Formation of hetero-oligomeric complexes of $\alpha \mathrm{A}$ - with $\alpha \mathrm{B}$-crystallin in bovine lens might completely block the accessibility of some of the thiols as observed by the Siezen et al. [32].

We have analyzed the kinetic profile of the thiolDTNB reactivity according to a simple double exponential equation

$$
\mathrm{A}=\mathrm{A}_{\mathrm{o}}+\mathrm{A}_{1}\left[1-\exp \left(-\mathrm{k}_{1} \cdot \mathrm{x}\right)\right]+\mathrm{A}_{2}\left[1-\exp \left(-\mathrm{k}_{2} \cdot \mathrm{x}\right)\right]
$$

The first term $\left(\mathrm{A}_{\mathrm{o}}\right)$ on the right hand side of Equation (1) represents the ordinate offset for a given system. It is the absorbance of the DTNB reaction product when the reaction zero time is set. The second term represents parameters for the fast reaction phase for thiol at position 142 and the third term for slow reacting thiol at position 131. A's stand for the reaction amplitude and the k's stand for the rate constant for the individual thiol. Since both the thiols react simultaneously, the individual amplitudes of the exponential terms are less meaningful. The Equation (1) has been reorganized to

$$
A=A_{o}-A_{1} \cdot \exp \left(-k_{1} \cdot x\right)-A_{2} \cdot \exp \left(-k_{2} \cdot x\right)
$$

All the kinetic data for the various systems were fitted according to this equation.
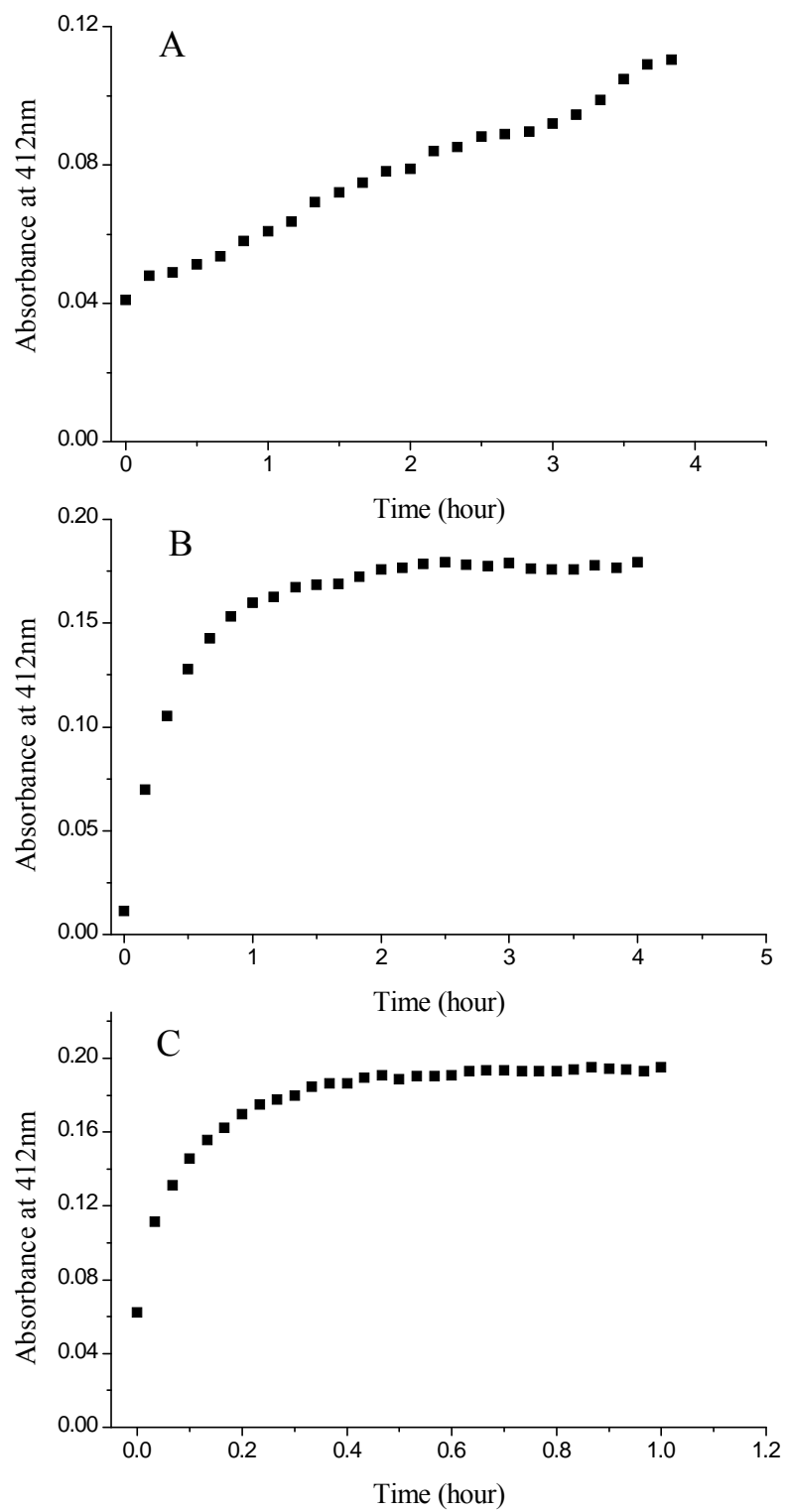

Figure 8. (A) DTNB kinetic profile of cys-131 of $\alpha$ A-crystallin in $1 \mathrm{M}$ urea, when cys-142 was blocked. $\alpha \mathrm{A}$-Crystallin concentration was $0.4 \mathrm{mg} / \mathrm{ml}$, in $50 \mathrm{mM}$ sodium phosphate buffer containing $1 \mathrm{mM}$ EDTA, pH 7.4, DTNB in 6-fold molar excess over the protein. Absorbance was measured at $412 \mathrm{~nm}$ as a function of time. Incubation time for the solution with $1 \mathrm{M}$ urea was $1 \mathrm{~h}$. (B) DTNB kinetic profile of cys-131 of $\alpha \mathrm{A}$-crystallin in $2 \mathrm{M}$ urea, when cys-142 was blocked. $\alpha \mathrm{A}$-Crystallin concentration was $0.4 \mathrm{mg} / \mathrm{ml}$, in $50 \mathrm{mM}$ sodium phosphate buffer containing $1 \mathrm{mM}$ EDTA, pH 7.4, DTNB in 6-fold molar excess over the protein. Absorbance was measured at $412 \mathrm{~nm}$ as a function of time. Incubation time for the solution with $2 \mathrm{M}$ urea was 1 h. (C) DTNB kinetic profile of cys-131 of $\alpha$ A-crystallin in $3 \mathrm{M}$ urea, when cys-142 was blocked. $\alpha \mathrm{A}$-Crystallin concentration was $0.4 \mathrm{mg} / \mathrm{ml}$, in $50 \mathrm{mM}$ sodium phosphate buffer containing $1 \mathrm{mM}$ EDTA, pH 7.4, DTNB in 6-fold molar excess over the protein. Absorbance was measured at $412 \mathrm{~nm}$ as a function of time. Incubation time for the solution with $3 \mathrm{M}$ urea was $1 \mathrm{~h}$. 
The fitted parameters for the thiol-DTNB reaction kinetics for various concentration of urea were reported in Table 1. Table 1 revealed that the rate constant for the thiol exposed at the surface (cys-142) was about 30 times faster than that of cys-131 under native conditions. As the structure of $\alpha \mathrm{A}$-crystallin loosened with addition of urea, there was an increase in rate constant till it reached a constant value of about $50 \mathrm{hr}^{-1}$ above $2.5 \mathrm{M}$ urea. From the studies of the stability of $\alpha$-crystallin [28,33,34], it is known that the mid-point of urea unfolding transition lies between 2.5 and $3 \mathrm{M}$ urea concentration. Thus in the native condition, the cys-142 though reacted quite fast was not fully exposed as was believed. Rate constant for cys-131 increased very little as urea concentration was increased from zero to $1.5 \mathrm{M}$ but on further increase in urea concentration $\mathrm{k}_{2}$ kept on increasing without reaching any limiting value. This indicated that during the initial stages of denaturation below $1.5 \mathrm{M}$ urea residue 131 was not much affected, although residue 142 got more exposed. Residue 131 started to get exposed only after cys-142 was almost fully exposed.

Thus the unfolding in this region of the sequence occurs in stages and perhaps proceeds from the junction of the flexible $\mathrm{C}$-terminal tail and $\alpha$-crystallin domain to wards the interior of the $\alpha$-crystallin domain. It also reveals that even at $4 \mathrm{M}$ urea, the $\alpha \mathrm{A}$-crystallin does not become fully extended as the observed $\mathrm{k}_{2}$ was much less than $\mathrm{k}_{1}$. The central $\alpha$-crystallin domain thus seems to have higher stability than the terminal domain.

The results for the effect of several structure-modulating agent on the thiol accessibility of $\alpha \mathrm{A}$-crystallin has also been analyzed by Equation (2) and the rate constants and other kinetic parameters were presented in Table 2. $\alpha \mathrm{A}$-Crystallin is a major $\alpha$-sheet protein. In presence of SDS its $\alpha$-sheet element gradually changed to helical configuration $[22,35]$. SDS also weakend the interactions between the subunits and consequently the oligomeric structure of $\alpha$ A-crystallin was broken down. Table 2

Table 1. Kinetic parameters for reaction of $\alpha \mathrm{A}$-crystallin with $\mathrm{DTNB}$ at $25^{\circ} \mathrm{C}$ in presence of urea.

\begin{tabular}{ccc}
\hline Reagent & $\mathbf{k}_{1}^{*}\left(\mathbf{h r}^{-1}\right)$ & $\mathbf{k}_{2}^{*}\left(\mathbf{h r}^{-1}\right)$ \\
\hline no urea & $28.81 \pm 0.915$ & $0.94 \pm 0.039$ \\
1 M urea & $32.21 \pm 1.03$ & $0.97 \pm 0.098$ \\
1.5 M urea & $36.65 \pm 1.12$ & $0.14 \pm 0.004$ \\
2 M urea & $41.57 \pm 1.13$ & $0.37 \pm 0.004$ \\
2.5 M urea & $50.27 \pm 1.23$ & $0.83 \pm 0.003$ \\
3 M urea & $49.08 \pm 1.23$ & $1.88 \pm .007$ \\
4 M urea & $49.28 \pm 1.26$ & $4.82 \pm 0.078$ \\
\hline
\end{tabular}

*Rate constants $\mathrm{k}_{1}$ and $\mathrm{k}_{2}$ were determined by equation $\mathrm{A}=\mathrm{A}_{\mathrm{o}}-\mathrm{A}_{1} \cdot \exp$ $\left(-\mathrm{k}_{1} \cdot \mathrm{x}\right)-\mathrm{A}_{2} \cdot \exp \left(-\mathrm{k}_{2} \cdot \mathrm{x}\right)$.
Table 2. Rate constants for reaction of $\alpha \mathrm{A}$-crystallin with $\mathrm{DTNB}$ at $25^{\circ} \mathrm{C}$ in presence of detergents and organic reagent.

\begin{tabular}{ccc}
\hline Reagent & $\mathbf{k}_{1}^{*}\left(\mathbf{h r}^{-1}\right)$ & $\mathbf{k}_{2}^{*}\left(\mathbf{h r}^{-1}\right)$ \\
\hline 0.5 mM SDS & $46.0 \pm 0.994$ & $1.33 \pm 0.023$ \\
1 mM SDS & $75.85 \pm 0.867$ & $3.77 \pm 0.164$ \\
2 mM SDS & $33.41 \pm 3.49$ & $6.33 \pm 0.057$ \\
1\% sodium deoxycholate & $26.42 \pm 0.996$ & $0.69 \pm 0.028$ \\
30\% TFE & $66.04 \pm 1.53$ & $1.27 \pm 0.050$ \\
\hline
\end{tabular}

showed that even $0.5 \mathrm{mM}$ SDS was able to substantially increase both $\mathrm{k}_{1}$ and $\mathrm{k}_{2}$ compared to its absence. Both the thiols of $\alpha \mathrm{A}$-crystallin are located in a region predicted to have a high propensity to form a pleated $\beta$-strand [36]. These predictions were experimentally supported by X-ray crystallographic observation of sHSP 16.5 and 16.9 where a similar cys- 131 within the $\alpha$-crystallin domain was found to lie in the $\beta 8$-strand [37,38]. As the $\beta$-sheet structure changes to $\alpha$-helix in presence of SDS with concomitant weakening of tertiary and quaternary structure, the exposure of cys-131 increases. In $1 \% \mathrm{Na}-$ deoxycholate the quaternary structure of $\alpha \mathrm{A}$-crystallin was broken down to a tetramer [39]. This loss of quarternary structure enhanced the cys-131 exposure without affecting the cys-142 (Table 2). TFE promotes helix formation without affecting the oligomeric size $[40,41]$. Here also low concentration significantly affected cys131, but not cys-142. However at 30\% TFE when extensive helix formation took place $\mathrm{k}_{1}$ was also significantly increased.

The decrease in the rate constant for the cys-142 on increase of SDS concentration from 1 to $2 \mathrm{mM}$ (Table 2) and decrease in the saturation absorbance in the kinetic profile (Figure 2(a)) pointed to a concentration dependent changes in thiol accessibility. Number of thiols that reacted with DTNB was not only less than 2 but it also decreased with increase in incubation time. The results indicated formation of S-S bond between cys-131 and cys-142. We have checked this by taking the amino acid cysteine and reacting with DTNB in presence of SDS, where a similar decrease in DTNB reaction was observed. Interestingly similar disulphide bond formation was also observed in cysteine in presence of urea, although the effect was not observed in $\alpha$ A-crystallin in urea. Since urea increased randomness of the molecule, such an interaction was not possible. We believe that structural modification by SDS, TFE, Tween-20, Na-deoxycholate somehow brought the two cysteine residues close together either by formation of an inward loop or by increasing hydrophobic interactions due to binding of the detergent chains. The formation of disulphide bonds in 
presence of SDS was found to be irreversible, as removal of SDS or Tween-20 etc. by dialysis after formation of $\mathrm{S}-\mathrm{S}$ bond did not revert it back to $-\mathrm{SH}$ form.

Binding of ATP to $\alpha$-crystallin has been reported by many workers [24,26,28] but the structural implications for such binding was poorly understood [42]. Our results showed that binding of ATP reduced $-\mathrm{SH}$ accessibility (Figure 4(c)). In $\alpha \mathrm{A}$-crystallin ATP binding site is located in the $\alpha$-crystallin domain, namely $\mathrm{Arg}^{112}$, $\mathrm{His}^{115}$, $\operatorname{Arg}^{116}, \operatorname{Arg}^{117}, \operatorname{Arg}^{119}[28,43]$, which is in close proximity to Cys ${ }^{131}$. It was suggested that ATP binding reoriented residues around the region despite making its structure somewhat more compact [28].

Heating of $\alpha$-crystallin solution led to increased exposure of hydrophobic residues on its surface $[1,44,45]$. However much of the heat induced changes in the secondary structural level were recovered on cooling back to room temperature [46]. There were irreversible tertiary structural changes due to heating [1]. The increase in pre-heating temperature did not significantly change $\mathrm{k}_{1}$ and $\mathrm{k}_{2}$ values (Table 3 ), but the accessibility of thiol was increased a little (Figure 5). Very similar result was obtained when $\alpha \mathrm{B}$-crystallin was complexed with $\alpha \mathrm{A}$ crystallin (in 1:1 ratio) and ATP was bound with $\alpha \mathrm{A}$ crystallin. In both the cases accessibility of thiol was little bit decreased. The results indicate that the sequence region between residues 131 to 142 is affected only marginally when $\alpha \mathrm{A}$-crystallin interacts with $\alpha \mathrm{B}$-crystallin or ATP. Complexation between $\alpha \mathrm{A}$ - and $\alpha \mathrm{B}$-crystallin at 3:1 ratio slightly increased the availability of both cys-142 and cys-131, but at 1:1 ratio, it blocked the access to cys-131. Contrary to these results, binding of substrate proteins such as carbonic anhydrase or lactate dehydrogenase reduced the accessibility of both the fast and slow reacting thiols. But $\mathrm{k}_{1}$ and $\mathrm{k}_{2}$ in case of $\mathrm{CA}$ were much higher than that of $\alpha \mathrm{A}$-crystallin alone, whereas those values of $\mathrm{k}_{1}$ and $\mathrm{k}_{2}$ for $\mathrm{LDH}$ were nearly same with $\alpha$ A-crystallin alone (Table 4). Since CA has a much lower molecular mass $(29 \mathrm{kDa})$ compared to oligomeric LDH $(124 \mathrm{kDa})$, at the same wt. ratio, there would be $\sim 4$ times the mole of CA than LDH. Substrate binding blocked the fast reacting thiol, as the saturation in $\mathrm{A}_{412}$ was reached at lower values corresponding to

Table 3. Effect of pre-incubation temperature on the rate constants for reaction of $\alpha \mathrm{A}$-crystallin with DTNB at $25^{\circ} \mathrm{C}$.

\begin{tabular}{ccc}
\hline Pre-incubation temperature $\left({ }^{\circ} \mathbf{C}\right)$ & $\mathbf{k}_{1}^{*}\left(\mathbf{h r}^{-1}\right)$ & $\mathbf{k}_{2}^{*}\left(\mathbf{h r}^{-1}\right)$ \\
\hline 25 & $29.15 \pm 1.81$ & $0.80 \pm 0.091$ \\
37 & $28.24 \pm 1.84$ & $0.63 \pm 0.082$ \\
45 & $30.35 \pm 1.99$ & $0.74 \pm 0.089$ \\
60 & $33.36 \pm 2.29$ & $0.95 \pm 0.091$ \\
70 & $30.95 \pm 2.13$ & $0.95 \pm 0.104$ \\
\hline
\end{tabular}

significantly less than one $-\mathrm{SH}$ (in case of $\mathrm{CA}$, the value was $\sim 0.5$ and for $\mathrm{LDH}$, it was $\sim 0.7$ ) available per $\alpha \mathrm{A}$ crystallin subunit. When $\alpha \mathrm{B}$-crystallin behaved as substrate of $\alpha$-crystallin, the accessibility of thiol was reduced but not so much as in the case of CA and LDH. This might be due to the fact that $\alpha \mathrm{B}$-crystallin has much higher molecular mass compared to CA and LDH. Thus bound substrate reduced - SH accessibility in accordance with its molar proportion in the complex. Our results reveal that $\alpha \mathrm{B}$-crystallin in 3:1 ratio may bind to $\alpha \mathrm{A}$ crystallin in a region different from those when $\alpha \mathrm{B}$ crystallin was in 1:1 ratio with $\alpha \mathrm{A}$-crystallin. This binding also differs from the binding of $\alpha \mathrm{A}$-crystallin with substrate proteins CA or LDH. These substrates may bind to region closer to the location of the thiols so that their accessibility is reduced.

The situation was different when the cys-142 was blocked and kinetics was measured with slow-reacting thiol cys-131. In case of SDS, comparison of $\mathrm{k}_{2}$ value of both unblocked and blocked $\alpha \mathrm{A}$-crystallin (Tables 2 and 5) showed that the value is more or less same indicating that in both the cases cys-131 was affected similarly. On the other hand, in case of $2 \mathrm{M}$ and $3 \mathrm{M}$ urea, $\mathrm{k}_{2}$ of blocked $\alpha \mathrm{A}$-crystallin was quite higher than that of unblocked $\alpha$ A-crystallin (Table 5). In addition to that, kinetic profile in both cases was also different. This indicates that the accessibility of one thiol depends on the other and this dependency is affected by different reagent.

\section{SUMMARY}

In this study, we have used DTNB as a tool to see the

Table 4. Effect of substrate binding on the rate constants for reaction of $\alpha \mathrm{A}$-crystallin with DTNB at $25^{\circ} \mathrm{C}$.

\begin{tabular}{ccc}
\hline Substrate & $\mathbf{k}_{1}^{*}\left(\mathbf{h r}^{-1}\right)$ & $\mathbf{k}_{2}^{*}\left(\mathbf{h r}{ }^{-1}\right)$ \\
\hline$\alpha$ A-crystallin without substrate & $29.15 \pm 1.48$ & $0.85 \pm 0.033$ \\
Lactate dehydrogenase & $27.57 \pm 2.52$ & $0.74 \pm 0.041$ \\
Carbonic anhydrase & $56.17 \pm 3.26$ & $1.6 \pm 0.12$ \\
\hline
\end{tabular}

Table 5. Rate constant for reaction of $\alpha \mathrm{A}$-crystallin (one thiol blocked) with DTNB at $25^{\circ} \mathrm{C}$ in presence of SDS and urea.

\begin{tabular}{cc}
\hline Reagent & $\mathbf{k}_{\mathbf{2}}^{*}\left(\mathbf{h} \mathbf{r}^{-\mathbf{1}}\right)$ \\
\hline $0.1 \mathrm{mM}$ SDS & $0.132 \pm 0.055$ \\
$0.3 \mathrm{mM}$ SDS & $6.96 \pm 0.327$ \\
1 M urea & $0.069 \pm 0.041$ \\
2 M urea & $2.35 \pm 0.061$ \\
3 M urea & $9.38 \pm 0.475$
\end{tabular}

${ }^{*}$ Rate constants $\mathrm{k}_{2}$ was determined by equation; $\mathrm{A}=\mathrm{A}_{\mathrm{o}}-\mathrm{A}_{1} \cdot \exp \left(-\mathrm{k}_{2} \cdot \mathrm{x}\right)$. 
effect on the accessibility of thiol so that we can get structural information of the thiol-containing hinge region of $\alpha$-crystallin during the binding with substrates and various perturbations. The accessibility of thiol was affected by the binding of substrates indicating that the substrate-binding sites are located around the thiol-containing region. The binding sites of $\alpha \mathrm{A}$-crystallin with $\alpha \mathrm{B}$-crystallin in 3:1 ratio are different from those of substrate proteins. This indicates that the mechanism of complex formation between $\alpha \mathrm{A}$ - and $\alpha \mathrm{B}$-crystallin in lens is quite different from that between $\alpha \mathrm{A}$-crystallin and substrates.

\section{ACKNOWLEDGEMENTS}

The authors would like to thank Mr. Dipak Chandra Konor for help with the experiments.

\section{REFERENCES}

[1] Das, K.P. and Surewicz, W.K. (1995) Temperature-induced exposure of hydrophobic surfaces and its effect on the chaperone activity of alpha-crystallin. FEBS Letters, 369, 321-325. http://dx.doi.org/10.1016/0014-5793(95)00775-5

[2] Biswas, A., Saha, S. and Das, K.P. (2002) Structural features of molecular chaperones: A possible micellar connection. Journal of Surface Science and Technology, 18, $1-24$.

[3] Saha, S. and Das, K.P. (2007) Unfolding and refolding of bovine alpha-crystallin in urea and its chaperone activity. The Protein Journal, 26, 315-326. http://dx.doi.org/10.1007/s10930-007-9074-3

[4] Saha, S. and Das, K.P. (2004) Relationship between chaperone activity and oligomeric size of recombinant human alphaA- and alphaB-crystallin: A tryptic digestion study. Proteins, 57, 610-617.

http://dx.doi.org/10.1002/prot.20230

[5] Narberhaus, F. (2002) Alpha-crystallin-type heat shock proteins: Socializing minichaperones in the context of a multichaperone network. Microbiology and Molecular Biology Reviews, 66, 64-93.

http://dx.doi.org/10.1128/MMBR.66.1.64-93.2002

[6] Sharma, K.K., Kaur, H., Kumar, G.S. and Kester, K. (1998) Interaction of 1,1'-bi(4-anilino)naphthalene-5,5'disulfonic acid with alpha-crystallin. The Journal of Biological Chemistry, 273, 8965-8970. http://dx.doi.org/10.1074/jbc.273.15.8965

[7] Sharma, K.K., Kumar, G.S., Murphy, A.S. and Kester, K. (1998) Identification of 1,1'-bi(4-anilino)naphthalene5,5'-disulfonic acid binding sequences in alpha-crystallin. The Journal of Biological Chemistry, 273, 15474-15478. http://dx.doi.org/10.1074/jbc.273.25.15474

[8] Datta, S.A. and Rao, C.M. (2000) Packing-induced conformational and functional changes in the subunits of alpha-crystallin. The Journal of Biological Chemistry, 275, 41004-41010.

[9] Pasta, S.Y., Raman, B., Ramakrishna, T. and Rao, C.M.
(2002) Role of the C-terminal extensions of alpha-crystallins. Swapping the C-terminal extension of alphacrystallin to alphaB-crystallin results in enhanced chaperone activity. The Journal of Biological Chemistry, 277, 45821-45828. http://dx.doi.org/10.1074/jbc.M206499200

[10] Santhoshkumar, P. and Sharma, K.K. (2001) Phe71 is essential for chaperone-like function in alpha A-crystallin. The Journal of Biological Chemistry, 276, 47094-47099. http://dx.doi.org/10.1074/jbc.M107737200

[11] Sharma, K.K., Kaur, H. and Kester, K. (1997) Functional elements in molecular chaperone alpha-crystallin: Identification of binding sites in alpha B-crystallin. Biochemical and Biophysical Research Communications, 239, 217-222. http://dx.doi.org/10.1006/bbrc.1997.7460

[12] Sharma, K.K., Kumar, R.S., Kumar, G.S. and Quinn, P.T. (2000) Synthesis and characterization of a peptide identified as a functional element in alphaA-crystallin. The Journal of Biological Chemistry, 275, 3767-3771. http://dx.doi.org/10.1074/jbc.275.6.3767

[13] Bova, M.P., Mchaourab, H.S., Han, Y. and Fung, B.K. (2000) Subunit exchange of small heat shock proteins. Analysis of oligomer formation of alphaA-crystallin and Hsp27 by fluorescence resonance energy transfer and site-directed truncations. The Journal of Biological Chemistry, 275, 1035-1042. http://dx.doi.org/10.1074/jbc.275.2.1035

[14] Feil, I.K., Malfois, M., Hendle, J., van der Zandt H. and Svergun, D.I. (2001) A novel quaternary structure of the dimeric alpha-crystallin domain with chaperone-like activity. The Journal of Biological Chemistry, 276, 1202412029. http://dx.doi.org/10.1074/jbc.M010856200

[15] Kokke, B.P.A., Leroux, M.R., Candido, E.P.M., Boelens, W.C. and de Jong, W.W. (1998) Caenorhabditis elegans small heat-shock proteins Hsp12.2 and Hsp12.3 form tetramers and have no chaperone-like activity. FEBS Letters, 433, 228-232. http://dx.doi.org/10.1016/S0014-5793(98)00917-X

[16] Leroux, M.R., Ma, B.J., Batelier, G., Melki, R. and Candido, E.P.M. (1997) Unique structural features of a novel class of small heat shock proteins. The Journal of Biological Chemistry, 272, 12847-12853. http://dx.doi.org/10.1016/S0014-5793(98)00917-X

[17] Das, K.P., Petrash, J.M. and Surewicz, W.K. (1996) Conformational properties of substrate proteins bound to a molecular chaperone alpha-crystallin. The Journal of Biological Chemistry, 271, 10449-10452.

http://dx.doi.org/10.1074/jbc.271.18.10449

[18] Lakowicz, J.R. (1983) Principles of fluorescence spectroscopy. Plenum Press, New York. http://dx.doi.org/10.1007/978-1-4615-7658-7

[19] Glazer, A.N. (1970) Specific chemical modification of proteins. Annual Review of Biochemistry, 39, 101. http://dx.doi.org/10.1146/annurev.bi.39.070170.000533

[20] Means, G.E. and Feeney, R.E. (1971) Chemical modifications of proteins. Holden-Day Sanfransisco California.

[21] Horwitz, J., Huang, Q.L., Ding, L.L. and Bova, M.P. (1998) Lens alpha-crystallin: Chaperone-like properties. Methods in Enzymology, 290, 365-383. http://dx.doi.org/10.1016/S0076-6879(98)90032-5 
[22] Bhattacharyya, J. and Das, K.P. (1999) Effect of surfactants on the prevention of protein aggregation during unfolding and refolding processes-Comparison with molecular chaperone-crystallin. Journal of Dispersion Science and Technology, 20, 1163-1178. http://dx.doi.org/10.1016/S0076-6879(98)90032-5

[23] Muchowski, P.J. and Clark, J.I. (1998) ATP-enhanced molecular chaperone functions of the small heat shock protein human alphaB crystalline. Proceedings of the $\mathrm{Na}$ tional Academy of Sciences, 95, 1004-1009. http://dx.doi.org/10.1016/S0076-6879(98)90032-5

[24] Palmisano, D.V., Groth-Vasselli, B., Farnsworth, P.N. and Reddy, M.C. (1995) Interaction of ATP and lens alpha crystallin characterized by equilibrium binding studies and intrinsic tryptophan fluorescence spectroscopy. Biochimica et Biophysica Acta, 1246, 91-97. http://dx.doi.org/10.1016/0167-4838(94)00176-H

[25] Rawat, U. and Rao, M.J. (1998) Interactions of chaperone alpha-crystallin with the molten globule state of xylose reductase. Implications for reconstitution of the active enzyme. The Journal of Biological Chemistry, 273, 94159423. http://dx.doi.org/10.1074/jbc.273.16.9415

[26] Wang, K. and Spector, A. (2000) alpha-crystallin prevents irreversible protein denaturation and acts cooperatively with other heat-shock proteins to renature the stabilized partially denatured protein in an ATP-dependent manner. European Journal of Biochemistry, 267, 47054712. http://dx.doi.org/10.1046/j.1432-1327.2000.01521.x

[27] Wang, K. and Spector, A. (2001) ATP causes small heat shock proteins to release denatured protein. European Journal of Biochemistry, 268, 6335-6345. http://dx.doi.org/10.1046/j.0014-2956.2001.02580.x

[28] Biswas, A. and Das, K.P. (2004) Role of ATP on the interaction of alpha-crystallin with its substrates and its implications for the molecular chaperone function. The Journal of Biological Chemistry, 279, 42648-42657. http://dx.doi.org/10.1074/jbc.M404444200

[29] Hasan, A., Smith, D.L. and Smith, J.B. (2002) Alpha-crystallin regions affected by adenosine 5'-triphosphate identified by hydrogen-deuterium exchange. Biochemistry, 41, 15876-15882. http://dx.doi.org/10.1021/bi026568x

[30] Kumar, M.S., Mrudula, T., Mitra, N. and Reddy, G.B. (2004) Enhanced degradation and decreased stability of eye lens alpha-crystallin upon methylglyoxal modification. Experimental Eye Research, 79, 577-583. http://dx.doi.org/10.1016/j.exer.2004.07.003

[31] Augusteyn, R.C., Hum, T.P., Putilin, T.P. and Thomson, J.A. (1987) The location of sulphydryl groups in alphacrystallin. Biochimica et Biophysica Acta, 915, 132-139. http://dx.doi.org/10.1016/0167-4838(87)90133-6

[32] Siezen, R.J., Coenders, F.G. and Hoenders, H.J. (1978) Three classes of sulfhydryl group in bovine alpha-crystallin according to reactivity to various reagents. Biochimica et Biophysica Acta, 537, 456-465. http://dx.doi.org/10.1016/0005-2795(78)90530-5

[33] Doss-Pepe, E.W., Carew, E.L. and Koretz, J.F. (1998) Studies of the denaturation patterns of bovine alpha- crystallin using an ionic denaturant, guanidine hydrochloride and a non-ionic denaturant, urea. Experimental Eye Research, 67, 657-679. http://dx.doi.org/10.1016/0005-2795(78)90530-5

[34] Sun, T.X., Akhtar, N.J. and Liang, J.J.N. (1999) Thermodynamic stability of human lens recombinant alphaAand alphaB-crystallins. The Journal of Biological Chemistry, 274, 34067-34071. http://dx.doi.org/10.1074/jbc.274.48.34067

[35] Biswas, A. and Das, K.P. (2004) SDS induced structural changes in alpha-crystallin and its effect on refolding. The Protein Journal, 23, 529-538. http://dx.doi.org/10.1007/s10930-004-7880-4

[36] Pasta, S.Y., Raman, B., Ramakrishna, T. and Rao, C.M. (2004) The IXI/V motif in the C-terminal extension of alpha-crystallins: Alternative interactions and oligomeric assemblies. Molecular Vision, 10, 655-662.

[37] Kim, K.K., Kim, R. and Kim, S.H. (1998) Crystal structure of a small heat-shock protein. Nature, 394, 595-599.

[38] van Montfort, R.L., Basha, E., Friedrich, K.L., Slingsby, C. and Vierling, E. (2001) Crystal structure and assembly of a eukaryotic small heat shock protein. Nature Structural Biology, 8, 1025-1030. http://dx.doi.org/10.1038/nsb722

[39] Kontorow, M., Horwitz, J., van Boekel, M.A.M., de Jong W.W. and Piatigorsky, J. (1995) Conversion from oligomers to tetramers enhances autophosphorylation by lens alpha A-crystallin. Specificity between alpha A- and alpha B-crystallin subunits. The Journal of Biological Chemistry, 270, 17215-17220. http://dx.doi.org/10.1074/jbc.270.29.17215

[40] Rajan, R. and Balaram, P. (1996) A model for the interaction of trifluoroethanol with peptides and proteins. International Journal of Peptide and Protein Research, 48, $328-336$ http://dx.doi.org/10.1111/j.1399-3011.1996.tb00849.x

[41] Srinivas, V., Santhoshkumar, P. and Sharma, K.K. (2002) Effect of trifluoroethanol on the structural and functional properties of alpha-crystallin. Journal of Protein Chemistry, 21, 87-95. http://dx.doi.org/10.1023/A:1014572110926

[42] Horwitz, J. (2003) Alpha-crystallin. Experimental Eye Research, 76, 145-153. http://dx.doi.org/10.1016/S0014-4835(02)00278-6

[43] Muchowski, P.J., Hays, L.G., Yates, J.R. and Clark 3rd, J.I. (1999) ATP and the core "alpha-crystallin" domain of the small heat-shock protein alphaB-crystallin. The Journal of Biological Chemistry, 274, 30190-30195. http://dx.doi.org/10.1074/jbc.274.42.30190

[44] Raman, B., Ramakrishna, T. and Rao, C.M. (1995) Temperature dependent chaperone-like activity of alphacrystallin. FEBS Letters, 365, 133-136. http://dx.doi.org/10.1016/0014-5793(95)00440-K

[45] Reddy, G.B., Das, K.P., Petrash, J.M. and Surewicz, W.K. (2000) Temperature-dependent chaperone activity and structural properties of human alphaA- and alphaB-crystallins. The Journal of Biological Chemistry, 275, 45654570. http://dx.doi.org/10.1074/jbc.275.7.4565 
[46] Maiti, M., Kono, M. and Chakraborti, B. (1988) Heatinduced changes in the conformation of alpha- and betacrystallins: Unique thermal stability of alpha-crystallin.
FEBS Letters, 236, 109-114.

http://dx.doi.org/10.1016/0014-5793(88)80295-3 